\title{
Relationship between surface conditions and subsequent rainfall in convective storms
}

\author{
Elfatih A. B. Eltahir and Jeremy S. Pal \\ Ralph M. Parsons Laboratory, Massachusetts Institute of Technology, Cambridge
}

\begin{abstract}
This paper describes the relationship between surface conditions (temperature and humidity) and subsequent rainfall. The focus is on convective storms that are forced and maintained locally due to conditional instability in the vertical distribution of atmospheric temperature. These storms are described using two probabilistic measures: (1) the probability of occurrence of storms given surface conditions and (2) the average storm rainfall. The surface conditions are described by a single variable: surface wet-bulb temperature. The proposed theoretical relationships are tested using an hourly data set on rainfall and wet-bulb temperature from the Amazon region. These observations confirm that both measures increase linearly with wet-bulb temperature. However, for the occurrence of any storm the wet-bulb temperature has to exceed a threshold of about $22^{\circ} \mathrm{C}$. The sensitivity of the frequency of storms to changes in the climatology of surface wet-bulb temperature is larger than the corresponding sensitivity of the average storm rainfall. These general concepts are applied in discussing the potential impact of changes in land cover on rainfall patterns using two specific examples: deforestation in the Amazon region and development of irrigation projects in the Columbia River basin.
\end{abstract}

\section{Introduction}

The scale and intensity of human activity in several regions of the world have reached a level that is likely to result in serious adverse impacts on the natural environment. In addition to the evident change in the chemical composition of the atmosphere, several large-scale human activities involve significant changes in land cover. Deforestation of the Amazon region [Bastable et al., 1993], draining of swamps at the sources of the Nile [Eltahir, 1989], expansion of irrigation projects on the Columbia River basin [Stidd, 1975], and extensive development of urban heat islands [Changnon, 1979] are examples for these activities. Any change in land cover is likely to modify the surface energy balance and the patterns of surface heat fluxes. However, when the scale of the changes in land cover is large enough, the atmosphere may respond to the perturbations in the lower boundary conditions through a complex set of processes and feedbacks that impact rainfall pattems and result in a regional climate change.

The physical processes that connect the changes in land cover to the potential climate change can be discussed in two broad categories.

1. The changes of local surface conditions in terms of temperature and specific humidity occur as a result of two processes that are closely related: (1) a modification of the surface energy balance that changes net surface radiation and the total flux of heat, including sensible and latent forms; this process is primarily driven by changes in surface albedo and surface emissions of terrestrial radiation (the latter is mainly due to changes in surface temperature); and (2) a modification of the partition of net surface radiation into sensible and latent heat fluxes (Bowen ratio); this process is primarily driven by changes

Copyright 1996 by the American Geophysical Union.

Paper number 96JD01380.

0148-0227/96/96J-01380\$09.00 in the moisture storage capacity of the soil layer and/or changes in the surface roughness. In general, a change in land cover from a dense vegetative cover to a sparse one or from a moist soil moisture condition into a dry one would be accompanied by a decrease in the net surface radiation and an increase in the Bowen ratio [Eltahir, 1996].

2. The other category is the triggering of significant atmospheric circulations at the mesoscale [Segal et al., 1988] and even at larger spatial scales [Eltahir and Bras, 1993]. The gradients in surface conditions (temperature and humidity) that result from any significant modification in the local surface energy balance, and in the partition of surface radiation may play an important role in the atmospheric dynamics at several scales ranging from the mesoscale to the regional scale.

The most important impact of any change in land cover is the potential modification of rainfall patterns. The rising air motion which leads to the formation of rainfall can be either associated with (1) large-scale atmospheric forcings such as those provided by orographic lifting, frontal systems in midlatitudes, and monsoon circulations in the tropics or (2) local instability in the vertical distribution of atmospheric temperature and atmospheric humidity. The degree of this instability is usually characterized by convective available potential energy (CAPE). Surface conditions (temperature and humidity) affect the magnitude of $\mathrm{CAPE}$; hence these conditions are important in rainfall processes that are associated with local instabilities. These weather systems define what we call in this paper "convective storms" and they usually occur during summer in midlatitudes and throughout most of the year in tropical regions. The focus of this paper is the relationship between convective storms and surface conditions. The motivation for studying convective storms is the fact that land surface processes play an important role in the dynamics of these weather systems. The triggering mechanism leading to the energy release and formation of rainfall in convective storms, which will be discussed in section 2 , is a nonlinear process that is partly controlled by surface conditions. 
This factor enhances the role of surface conditions in the dynamics of these systems.

The studies by Zawadzki and Ro [1978] and Zawadzki et al. [1981] explored the relationship of convective storms and the mesoscale thermodynamic variables. Their studies involved analysis of data from a network of meteorological stations located near Montreal during summer. A significant correlation was found between maximum and mean observed rainfall rates and mesoscale thermodynamic variables such as convective energy and static potential energy. Zawadzki et al. [1981] analyze surface observations as well as upper air soundings. However, in this paper we focus on the relation between surface conditions and rainfall without considering conditions in the upper troposphere. Implicit in our approach is the assumption that surface conditions exhibit significantly larger variability compared to conditions in the upper troposphere.

The objective of this paper is to develop a theoretical framework for describing the sensitivity of convective rainfall to changes in surface conditions and, in particular, to changes in temperature and humidity. The variable that has been chosen to characterize surface conditions is wet-bulb temperature: a directly observable quantity that characterizes both surface temperature and surface humidity. Wet-bulb temperature is a good measure of moist static energy and surface entropy and responds to variability in the total flux of heat, including sensible and latent forms. Williams and Reno [1993] analyzed surface and upper air observations from several regions and found significant correlation between wet-bulb temperature and CAPE. This relation is characterized by a threshold of wet-bulb temperature that has to be reached for any significant amount of CAPE to exist. As described in the next section, the concept of CAPE plays a central role in the description of convective storms.

The approach followed in this paper combines physical and probabilistic descriptions of convective storms. This methodology addresses one of the critical research questions raised by the recent report Opportunities in the Hydrologic Sciences [National Research Council (NRC), 1991]: How can the necessary and fundamental links between the deterministic (dynamic) and the stochastic models of rainfall fields be established? The theory outlined in the next section attempts to address this question for the case of point rainfall. The statistical characteristics of convective rainfall are related to a single atmospheric variable using physical concepts and arguments. The resulting hybrid (physical-statistical) model of rainfall has several applications that go beyond the typical uses of stochastic rainfall models for simulation purposes and include issues such as sensitivity of rainfall to changes in land cover. The following sections illustrate some of these applications.

The relationship between rainfall and surface wet-bulb temperature is developed in the next section. Observations on rainfall and surface wet-bulb temperature from the Amazon region are described and analyzed in section 3. The proposed relation between surface wet-bulb temperature and rainfall is applied in exploring some of the potential pathways between changes in land cover and the impact on rainfall using two specific examples. These applications are described in section 4 . The conclusions of this paper are described in section 5 .

\section{Theory}

The physical processes leading to convective rainfall are divided into (1) triggering of moist convection and (2) release of potential energy and formation of rainfall. The first process controls the rate of occurrence of storms; the second process controls the magnitude of storm rainfall. In the following subsections both of these processes are considered.

\section{Triggering of Moist Convection}

Dry convection is the dominant process that is responsible for mixing in the atmospheric boundary layer. As a result, the temperature profile in this layer follows a dry adiabatic lapse rate: atmospheric temperature decreases with elevation at a rate of about $10^{\circ} \mathrm{C}$ per kilometer. The Clausius-Clapeyron relation dictates that the saturation mixing ratio should decline accordingly in the same layer. However, because of the principle of conservation of water mass the moisture profile in the boundary layer is characterized by a constant mixing ratio. As a result, at some atmospheric level a rising air parcel that follows a dry adiabat should reach saturation. This level is known as the lifting condensation level (LCL). The likelihood of occurrence of moist convection is a function of the atmospheric temperature distribution in the layer that is located above the LCL. These conditions dictate if a rising air parcel, that is saturated at the LCL, would experience negative or positive buoyancy aloft. The level above which such a parcel would experience positive buoyancy is known as the level of free convection (LFC). In theory, convection is triggered when the top of the boundary layer coincides with the LCL and the LFC. However, if the depth of the boundary layer is below the LCL or the LFC, convection will not be triggered. Under such conditions, some external forcing is necessary for triggering of moist convection. This section provides a general idealized description of moist convection processes. In reality the turbulent processes associated with formation of rainfall are more complex and difficult to describe with few scenarios or a simple model.

These basic concepts are illustrated in Figure 1a which shows an atmospheric sounding, that may be typical for the tropics and midlatitudes during summer, and surface conditions as described on a tephigram. The surface wet-bulb temperature is the temperature that corresponds to the intersection of the pseudoadiabat and the line of constant surface pressure. Figure la describes the impact of varying the wet-bulb temperature assuming that the surface temperature and hence the dry adiabat are held fixed. For the same dry adiabat but assuming different humidity conditions, the wet-bulb temperature in the relatively humid condition is larger than the value of the same variable under the dry condition $\left(T_{w 2}>T_{w 1}\right)$. But, $L C L_{2}$ coincides with the top of the boundary layer which is below $L C L_{I}$. Hence inspite of the similar depths that are assumed to characterize the boundary layer in the two different scenarios of Figure la, convection is triggered in the relatively humid condition but the same process is inhibited in the dry one. In summary, for given surface temperature conditions the likelihood of triggering of moist convection increases with wet-bulb temperature.

Similar arguments can be developed by considering Figure $1 \mathrm{~b}$ which shows the impact of varying surface temperature while holding the mixing ratio fixed. For the same moisture conditions but assuming different surface temperature conditions, $T w_{2}$ in the relatively warm condition is larger than $T w_{1}$ in the relatively cold condition. However, we would expect the depth of the boundary layer to increase with surface temperature. Hence inspite of the fact that $L C L_{2}>L C L_{1}$, convection is triggered in the relatively warm condition and inhibited in the cold one. In summary, for a given surface humidity conditions the likelihood 


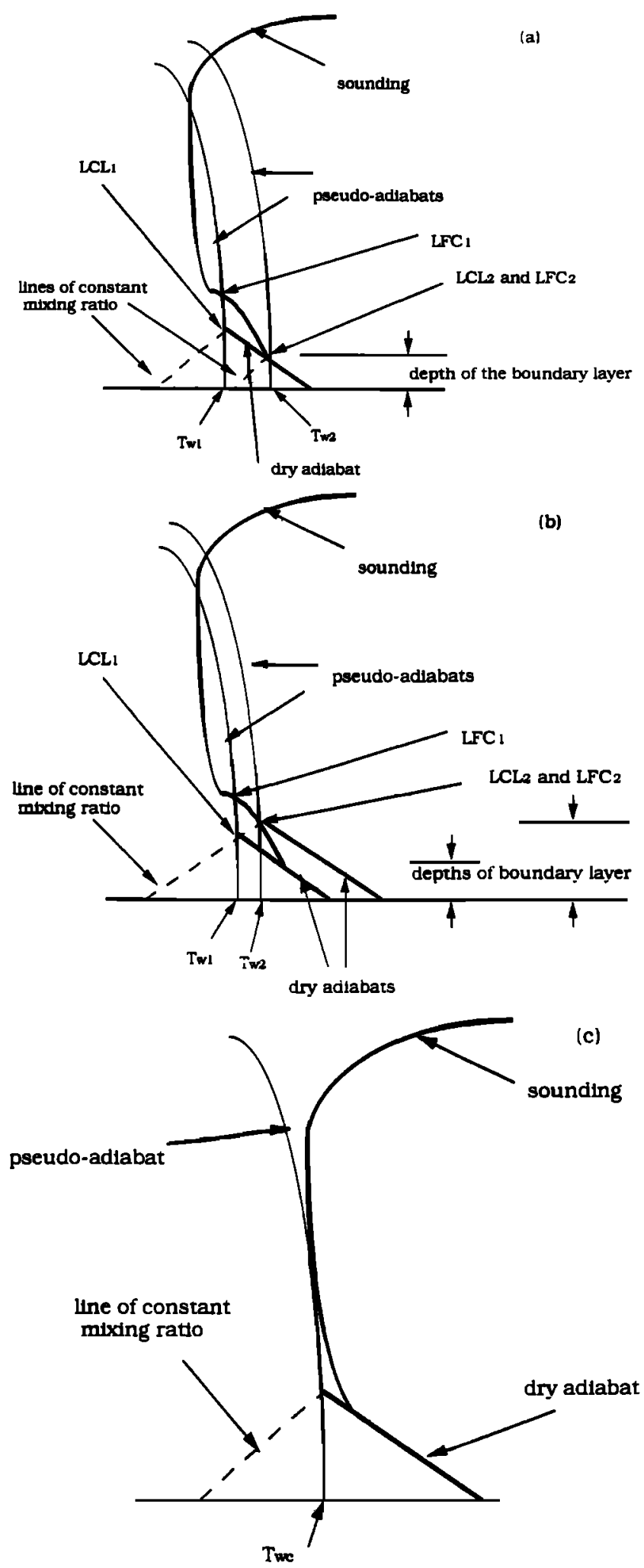

Figure 1. Role of Tw in the triggering of moist convection: (a) constant surface temperature, (b) constant mixing ratio, (c) critical wet-bulb temperature.

of triggering of moist convection increases with wet-bulb temperature. Finally, it is important to realize that for any atmospheric temperature distribution, there is a minimum wetbulb temperature that is needed in order for moist convection to occur. This concept is illustrated by Figure 1c. If the wet-bulb temperature is below this critical value, $T_{w c}$, then the probability that moist convection occurs freely is exactly zero. Under such conditions, any air parcel rising from the surface would experience negative buoyancy at all levels.

Although surface wet-bulb temperature is an important variable in describing the processes leading to moist convection, this quantity is by no means the only important variable. The height of the boundary layer, the atmospheric temperature distribution above the boundary layer, and the relative contributions of temperature and mixing ratio to $T_{w}$, among other variables, are important in describing the triggering process. For example, Figure $1 \mathrm{~b}$ illustrates the important role of the processes that determine the height of the boundary layer. Hence if the analysis described in this paper is to be extended to include more than one variable that describes surface conditions, the height of the boundary layer would be a natural choice. However, since a simple relation is sought between rainfall and surface conditions, these other variables are not included in the proposed approach. As a result, triggering of moist convection is described using a probabilistic measure that is a function of surface wet-bulb temperature only. Implicit in the use of this probabilistic framework is the recognition that some of the relevant important physical variables are not included; otherwise we would use a deterministic relation that predicts the triggering of convection given knowledge of the relevant physical variables, including wet bulb temperature, and height of the boundary layer, among others.

On the basis of the above discussion we conclude that the likelihood of occurrence of convective storms increases as surface wet-bulb temperature increases. Hence the probability of occurrence of a convective storm given certain surface conditions, or given $T_{w}$, denoted by $P\left(R T_{w}\right)$, should be an increasing function of $T_{w}$. The exact form of this function will be explored using observations in section 3. Since wet-bulb temperature varies in time, a probability of occurrence of a certain $T_{w}, P\left(T_{w}\right)$, is defined to measure the likelihood of prevalence of certain surface conditions. Then, the product of $P\left(R / T_{w}\right)$ and $P\left(T_{w}\right)$ is another function of $T_{w}$, denoted by $P\left(R, T_{w}\right)$. The latter describes the probability of occurrence of certain surface conditions and occurrence of a storm.

$$
P\left(R, T_{w}\right)=P\left(R / T_{w}\right) P\left(T_{w}\right)=f\left(R, T_{w}\right) d T_{w}
$$

where $f\left(R, T_{w}\right)$ is the corresponding probability density function. All these probabilistic measures can be estimated directly from suitable surface observations.

The relation between storm rainfall (total amount of rainfall in any single storm) and $T_{w}$ can be expressed in a general form by the function $R=G\left(T_{w}\right)$. The form of this function will be described in the next subsection. Hence the daily average rainfall for any season is given by

$$
\bar{R}=\int G(T w) f(R, T w) d T w
$$

This relation expresses the dependence of climatological rainfall amount in terms of two functions; $f$ and $G$, which represent the two following processes: triggering of moist convection, and the formation of storm rainfall.

\section{Release of Potential Energy and Formation of Rainfall}

This section addresses the development of the physical relation $G\left(T_{w}\right)$. Under radiative convective equilibrium 
conditions, radiation de-stabilizes the atmosphere, moist convection works to stabilize the vertical distribution of atmospheric temperature. Based on this basic concept, we propose that rainfall associated with any convective storm is directly proportional to the latent energy release that is needed to bring the atmosphere from instability to moist neutrality; we suggest that this potential storm rainfall, $R$, is given by

$$
R=\frac{l}{L} \int_{L F C}^{L N B} \rho C_{P}\left(T_{m a}-T_{a}\right) d z=\frac{C_{P}}{L g} \int_{L N B}^{L F C}\left(T_{m a}-T_{a}\right) d p
$$

where $L$ is latent heat of vaporization, $C_{p}$ is specific heat capacity of dry air at constant pressure, $p$ is pressure, $z$ is elevation, $g$ is gravity acceleration, $L F C$ is level of free convection, $L N B$ is the level of neutral buoyancy, $T$ is temperature, $\rho$ is air density, ma denotes moist adiabat, and a denotes air. This formulation is similar to that suggested by Manabe et al. [1965] known as moist convective adjustment, except that we define rainfall as total storm rainfall. The use of storm rainfall instead of instantaneous rainfall is consistent with the scheme of Betts [1986].

CAPE is a useful measure of the potential energy available for conversion into kinetic energy by undiluted parcels of air rising from the boundary layer and following a moist adiabatic trajectory. CAPE is given by

$$
C A P E=R_{g} \int_{L N B}^{L F C}\left(T_{m a}-T_{a}\right) d \ln p
$$

where $R_{\mathrm{g}}$ is the ideal gas constant for dry air. CAPE is a function of the thermodynamic properties of the boundary layer air and the vertical profile of atmospheric temperature. However, for any climatic regime (region and season) the vertical profile of temperature in the upper atmosphere is less variable compared to surface conditions. Williams and Renno [1993] studied the

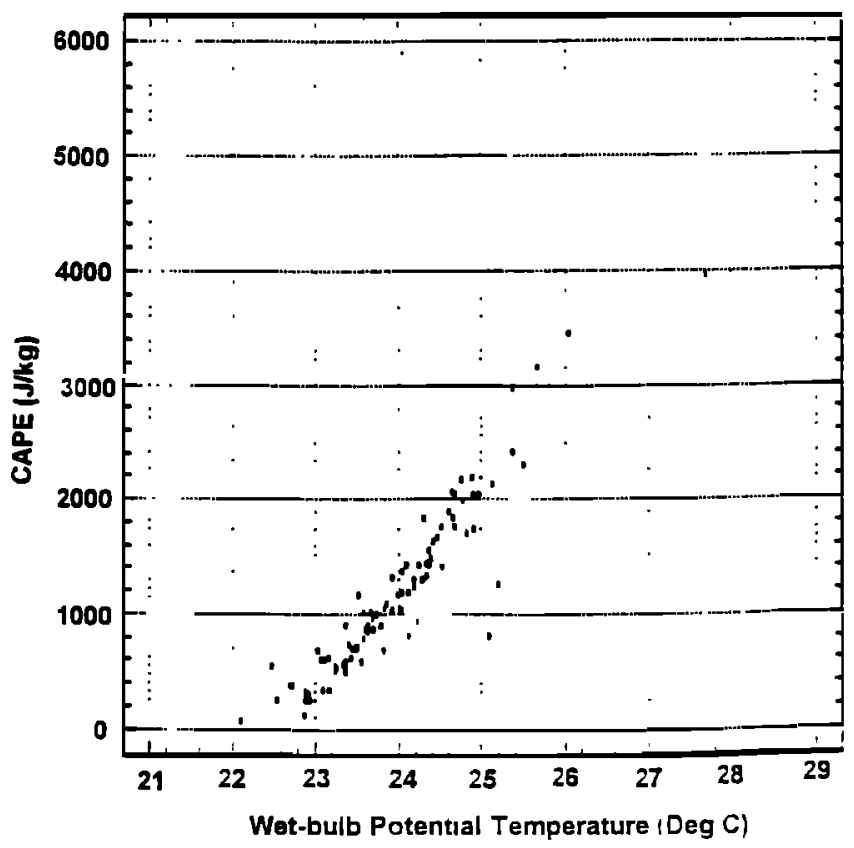

Figure 2. Convective available potential energy (CAPE) versus wet-bulb potential temperature for an ineversible process in Belem, South America [from Williams and Renno, 1993].

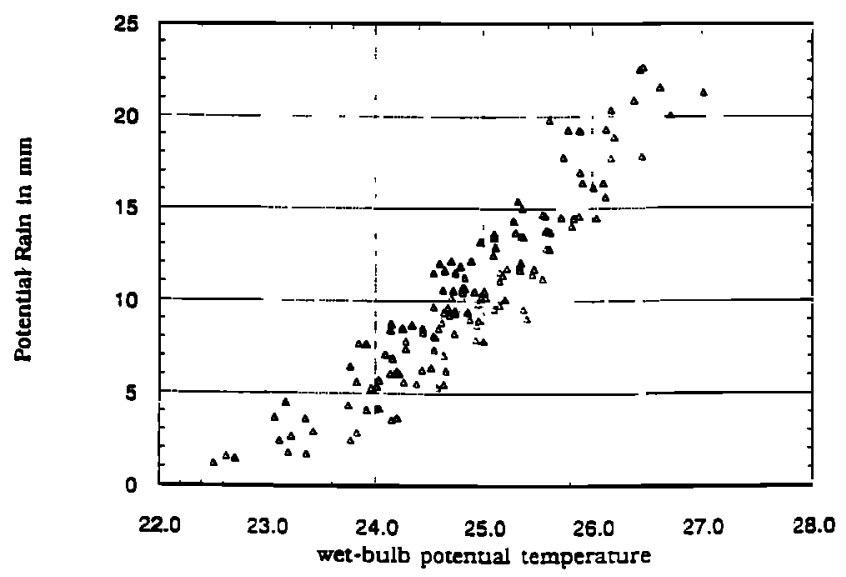

Figure 3. Potential rainfall versus wet-bulb potential temperature, Darwin, Australia; the source of the data is AMEX (Australian Monsoon Experiment) [Williams and Renno, 1993].

relation of CAPE to surface conditions. Based on extensive data analysis, they found a simple linear relation between CAPE and surface wet-bulb temperature.

$$
C A P E=\alpha(T w-T w c)
$$

The constants $\alpha$ and $T_{w c}$ are characteristics of the climatic regime. Figure 2 describes their observations for Belem in the Amazon region. The critical wet-bulb temperature $T_{w c}$ is observed to be about $22^{\circ} \mathrm{C}$.

The two integrals in equations (3) and (4) are identical except for the independent variable of integration ( $p$ versus $\ln p$ ). If the distribution of the heating due to condensation is a unique function of pressure, then the two integrals should be linearly related. Figure 3 shows observations on $R$, computed according to equation (3), and $T_{w}$ from Darwin, Australia. These observations confirm the existence of a simple linear relation between potential rainfall, $R$, and $T_{w}$ of the following form:

$$
R=\beta\left(T_{w}-T_{w r}\right)
$$

where $\beta$ and $T_{w r}$ are constants characteristic of the climatic regime. They represent the slope and the intercept in the proposed linear relation between storm rainfall and wet-bulb temperature. This linear relation defines the form of the function G. (The term potential rainfall is used to distinguish between observed rainfall and rainfall that is defined by equation (3)). Substitution for $R$ from equation (6) into equation (2) results in

$$
\bar{R}=\int_{0}^{\infty} \beta(T w-T w r) f(R, T w) d T w
$$

which relates the daily average rainfall and surface conditions.

\section{Observations}

The previous section presents two hypotheses linking convective rainfall to surface conditions. The first hypothesis states that the likelihood of occurrence of a convective storm increases as wet-bulb temperature increases. The second hypothesis states that storm rainfall is a linear function of wetbulb temperature. These two hypotheses will be tested using data from the Amazon Region Micrometeorological Experiment (ARME). 
Amazon Region Micrometeorological Experiment (ARME)

ARME is a field study that involved collection of hourly meteorological measurements from a tower over the Amazon rain forest during the period of September 1983 to August 1985 [Shuttleworth,1988]. The site of the tower is representative of the native vegetation and typical topography of the Amazon. It is located at $2^{\circ} 57^{\circ} \mathrm{S}, 59^{\circ} 57^{\prime} \mathrm{W}$ in the Reserva Florestal Ducke. The following analysis uses the observations on rainfall, temperature, and wet-bulb temperature.

\section{Methods of Analysis}

A storm event is defined as any rainfall of any duration, not necessarily continuous, followed and preceded by at least 3 hours of no rain. This definition is consistent with that of Lloyd [1990] who worked with the same data set. Rainfall duration is defined as the number of hours over which a rainfall event occurs. It may include gaps in rainfall that do not exceed 3 hours. As previously stated, the data were measured in hourly increments. Therefore if an event duration exceeds 1 hour, it is assumed to start half an hour after the starting hour and to end half an hour before the ending hour [Lloyd, 1990]. This minimizes errors in computing duration to a maximum of 1 hour.

Because of the diumal cycle of solar radiation the triggering of moist convection is a nonstationary process. Rainfall in the Amazon region typically occurs in the midafternoon (see Figure 4 ), when the boundary layer is thickest. As one may expect, this corresponds to the peak of the diurnal cycle of temperature, which is shown in Figure 5a. As shown in Figure 5b, the peak of the diurnal cycle for wet-bulb temperature occurs one or two hours before the peak of the diumal cycle of temperature. Although the probability analysis reported in this paper is performed for events that are triggered in the midafternoon hours (the range from 1400 to 1600 ), similar results are found for other times of the day.

The wet-bulb temperature measured one hour before a storm event is used in assessing the relationship between wetbulb temperature and storm rainfall. Similarly, in determining

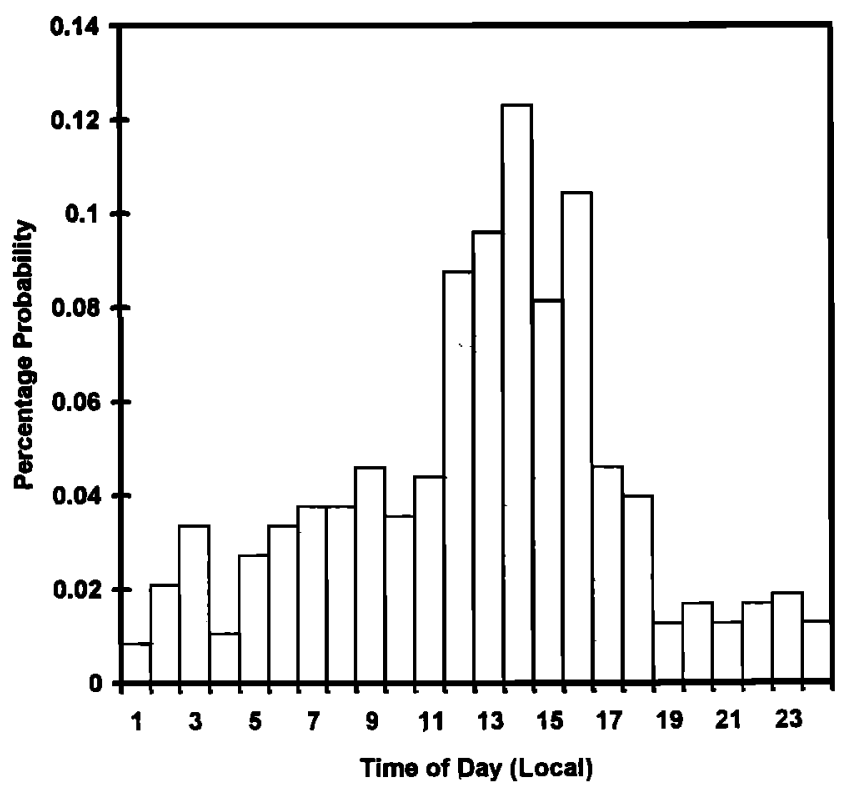

Figure 4. Probability of rainfall occurring during the different hours of the day at Reserva Ducke.
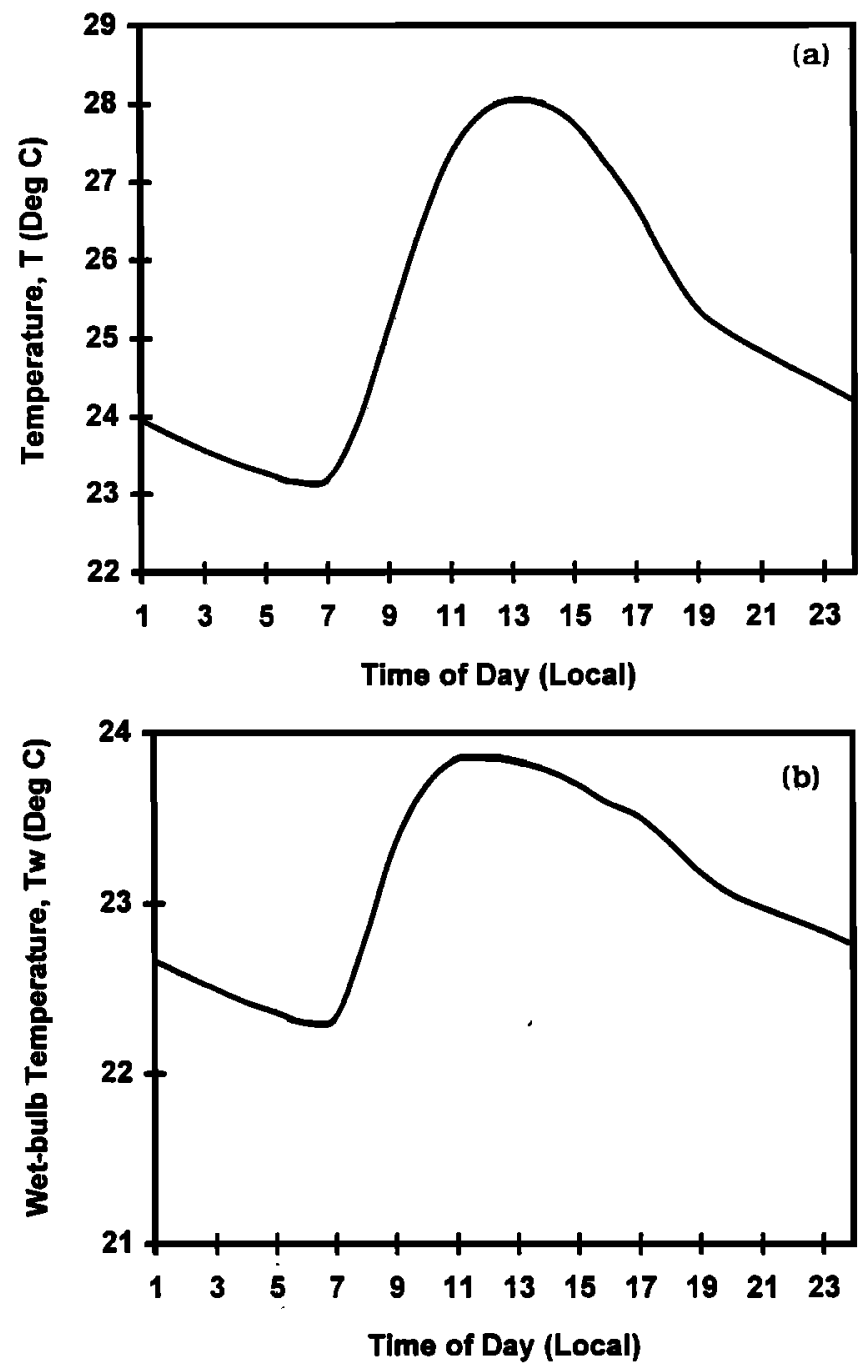

Figure 5. (a) Diurnal cycle of surface temperature for Reserva Ducke and (b) diurnal cycle of wet-bulb temperature.

the probability of rainfall given wet-bulb temperature, $\mathrm{P}\left(R / T_{w}\right)$, the wet-bulb temperature observed in the hour before the storm arrival is used. As alluded to in the introduction, this study is only concerned with convective storms that are forced and maintained locally due to conditional instability in the vertical distribution of temperature. The data set, however, includes some rainfall events that are forced by large-scale atmospheric circulations. To test the above theory, it is necessary to remove these large-scale events from the data. The distinction between the different types of storms was achieved by removing the events with long durations. Convective storms are assumed to have relatively short durations compared with events that are forced by large-scale circulations. The main results are obtained assuming a duration of 5 hours to be the border between the two types of storms. However, this assumption is tested and the analysis is repeated, assuming several different values for this duration threshold. As shown in Figure 6, approximately $90 \%$ of all the storms at the site have durations of 6 hours or less and approximately $70 \%$ have durations of 3 hours or less. The local convective storms, defined with a maximum duration of 5 hours, account for about $78 \%$ of all the events and contribute about $55 \%$ of the total rainfall collected during the 2 years of the study. 


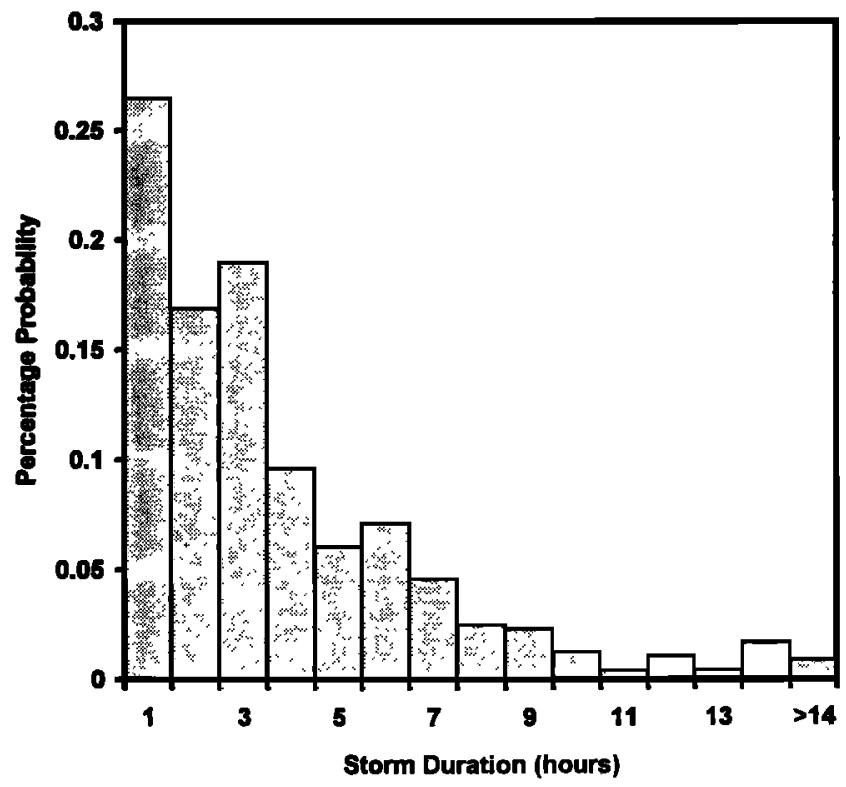

Figure 6. Probability of storm duration for Reserva Ducke.

\section{Results}

Figure 7 shows estimates of $\mathrm{P}\left(R / T_{w}\right)$ that are obtained considering only the convective storms that are triggered in the midafternoon. Although the maximum duration of the storms considered in Figure 7 is limited to 5 hours, similar results are found assuming maximum durations of 6 and 4 hours. The correlation coefficient for the observed relation between $\mathrm{P}\left(R / T_{w}\right)$ and $T_{w}$ is about 0.9 . These results confirm that $\mathrm{P}\left(R / T_{w}\right)$ is indeed an increasing and almost linear function of $T_{w}$. The threshold value for wet-bulb temperature, $T_{w c}$, is found to be about $22^{\circ} \mathrm{C}$, which is very similar to the value of the threshold estimated by Williams and Renno [1993] for the relationship between wetbulb temperature and CAPE in the same region. If the midafternoon, wet-bulb temperature is below this threshold; there is very little probability for the occurrence of a storm.

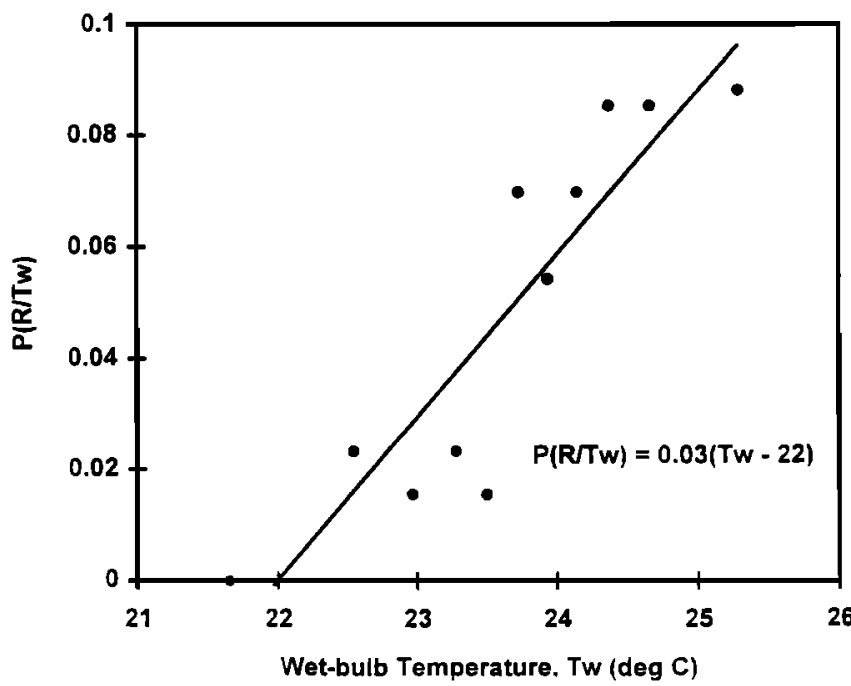

Figure 7. Probability of rainfall given wet-bulb temperature for Reserva Ducke for storms triggered during the period from 1400 to 1600 . Each estimate of the probability is computed using about 130 observations. The equation for $\left(P\left(R / T_{w}\right)\right)$ and is shown in the bottom right-hand comer.

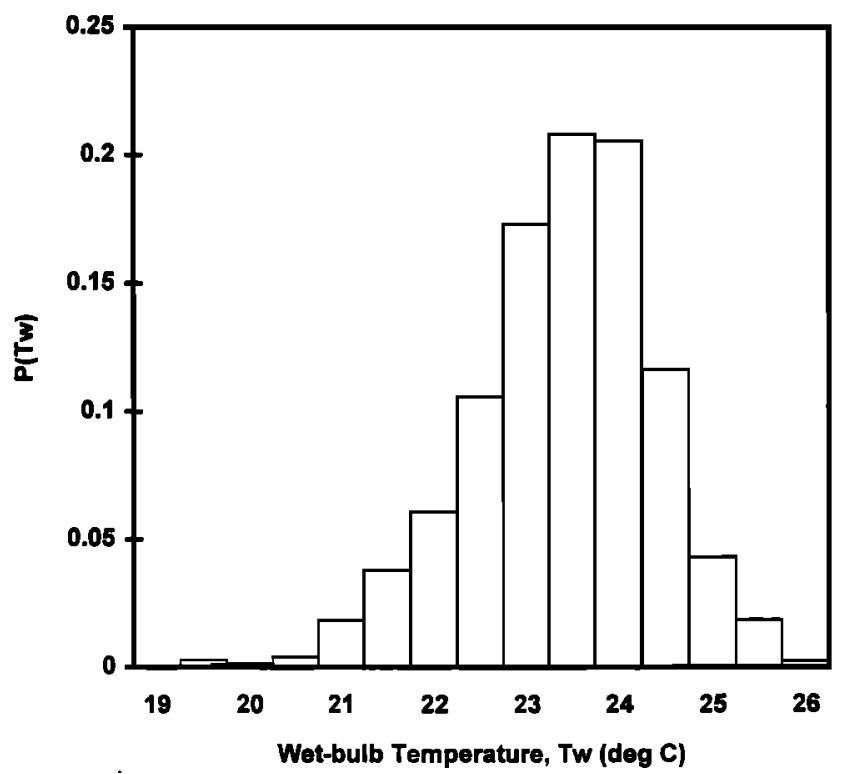

Figure 8. Probability mass function of wet-bulb temperature for Reserva Ducke for storms triggered during the period from 1400 to 1600 .

Figure 8 shows the probability mass function for wet-bulb temperature in the midafternoon over the Amazon forest. About $10 \%$ and $30 \%$ of the observed values of wet-bulb temperature fall below $22^{\circ} \mathrm{C}$ and $23^{\circ} \mathrm{C}$, respectively. Hence under the current climate the midafternoon wet-bulb temperature for about $10 \%$ of the days falls below the absolute threshold of $22^{\circ} \mathrm{C}$ that is needed for triggering of moist convection. However, for sensitivity analysis we assume that some change in land cover shifted the distribution of wet-bulb temperature to the left by about $1{ }^{\circ} \mathrm{C}$; see Figure 9a. As a result, about $30 \%$ of the mass associated with this distribution will fall in the inhibition range. More importantly, most of the mass under the probability distribution, $\mathrm{P}\left(T_{w}\right)$, will fall within the portion of the linear curve $\mathrm{P}\left(R / T_{w}\right)$ with relatively small probability. This discussion is illustrated using Figure 9. By comparing the sum of the two probability mass functions, $\mathrm{P}\left(R, T_{w}\right)$, in Figure $9 \mathrm{~b}$, we estimate that the frequency of occurrence of storms in the midafternoon of any day in the Amazon region would decrease by about $50 \%$ in response to a cooling of $1^{\circ}$ in the average wet-bulb temperature.

The results of the analysis on the relation between storm rainfall and wet-bulb temperature are presented in Figure 10. Each data point displayed in Figure 10 is an estimate of $R$ obtained by averaging from an equal number of observations. These observations confirm the existence of a significant linear relation between $R$ and $T_{w}$. The correlation coefficient is about 0.76 . Since the diurnal cycle has negligible effect on the relation between convective rainfall and wet-bulb temperature, this analysis is carried using the data for all the hours. The maximum storm duration is assumed to be 5 hours. However, similar results are obtained when limiting the maximum duration to 4 or 6 hours. The sensitivity of storm rainfall to wet-bulb temperature, $\beta$, is equivalent to the slope of the regression line in Figure 10. This slope is about $2.4 \mathrm{~mm} /{ }^{\circ} \mathrm{C}$.

If, as a result of any change in land cover, the distribution of $\mathrm{P}\left(T_{w}\right)$ shifts to the left by about $1^{\circ} \mathrm{C}$ as shown in Figure 9a, more of that distribution will fall under a portion of the linear 

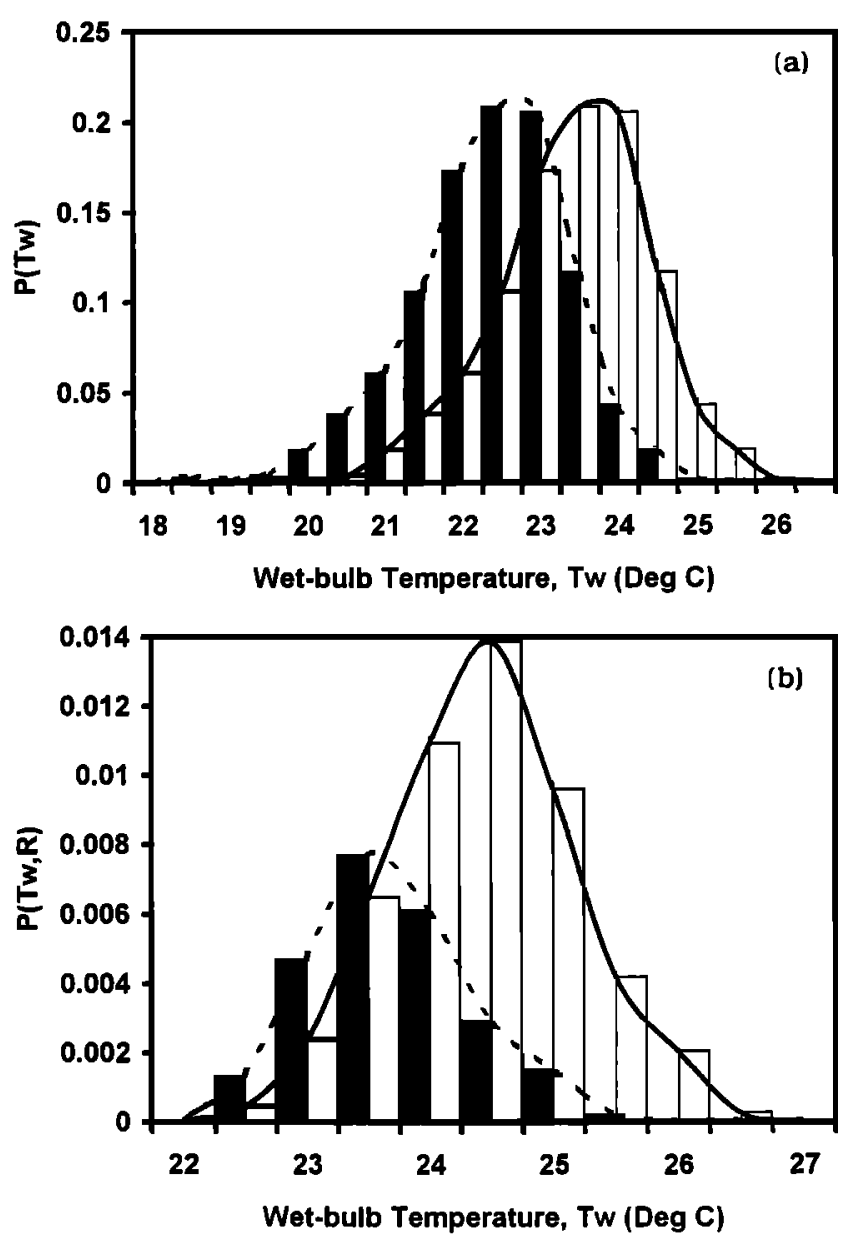

Figure 9. (a) Probability mass function of wet-bulb temperature and (b) joint probability mass function of rainfall and wet-bulb temperature where solid line is natural state and dashed line is the disturbed state which result from a reduction of average wet-bulb temperature by $1^{\circ} \mathrm{C}$.

curve, $\mathrm{G}(\mathrm{Tw})$, which creates less rainfall. Hence the average storm rainfall will decrease with any decrease in the average wet-bulb temperature. Using equation (7), together with the two distributions of Figure $9 \mathrm{~b}$, and the relation of Figure 10, we estimate that in response to the cooling of Figure 9a, the daily average rainfall would decrease by about $60 \%$, implying that the average storm rainfall (given the occurrence of a storm) would decrease by about $15 \%$.

Since wet-bulb temperature is a function of both temperature and humidity, similar analyses are performed for the midafternoon hours using surface temperature and humidity instead of wet-bulb temperature. For the probability of occurrence of storms the data reveal a correlation of about 0.69 for both surface temperature and humidity. These values are significantly smaller than that obtained for the correlation between wet-bulb temperature and rainfall, 0.9. However, the same data reveal that the relation of storm rainfall to temperature or humidity is rather insignificant.

\section{Applications}

As argued in the introduction, our understanding of the relationship between rainfall and surface conditions should help in identifying the pathways between any changes in land cover and their potential impacts on rainfall patterns. In this section the proposed relation between wet-bulb temperature and rainfall will be applied in discussing two different cases that involve changes in land cover: deforestation in the Amazon region and development of irrigation in the Columbia River basin. In the case of the Amazon basin the focus is on explaining the reported results from several numerical simulations using general circulation models (GCMs). While in the case of the Columbia basin, the focus is on the observed trends in summer rainfall following the development of a large-scale irrigation project.

Both deforestation and development of irrigation involve significant changes in vegetative cover. Eltahir [1996] described the role of vegetation in modifying boundary layer entropy, arguing that any increase in vegetative cover or density would enhance the boundary layer entropy. Since surface wet-bulb temperature is one measure of moist static energy and is closely associated with moist entropy, $T_{w}$ is likely to increase with vegetative density. Hence everything else being the same, we would expect Tw to increase following development of irrigation projects and to decrease following deforestation. The analysis presented in this paper suggests that we should then expect some enhancement of convective rainfall following irrigation and a decline in rainfall levels following deforestation.

The results of several GCM studies, Lean and Warrilow [1989]; Nobre et al. [1991]; Dickinson and Kennedy [1992]; Henderson-Sellers et al. [1993]; Lean and Rowntree [1993]; Diremeyer and Shukla [1994], suggest that large-scale deforestation in the Amazon region will reduce local rainfall. The same studies predict an increase in surface temperature and drying of the boundary layer as a result of large-scale deforestation. The immediate question that arises is how the simulated changes in rainfall came about? are they triggered by changes in large-scale circulation, or by changes in local surface conditions? or both? If the decrease in the simulated rainfall

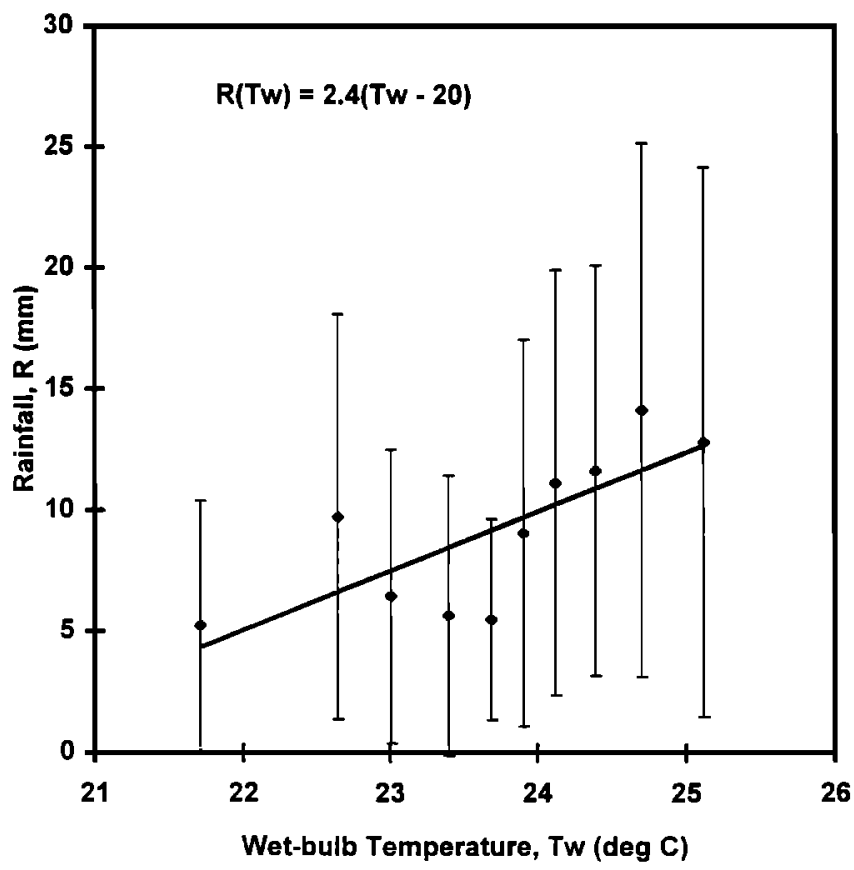

Figure 10. Storm rainfall versus wet-bulb temperature for durations of 5 hours or less. Each point represents the average from 37 data points (the error bars represent one standard deviation). The equation for $R\left(T_{w}\right)$ is shown in the top left-hand comer. 
was initially forced by a change in the large-scale atmospheric circulation, then we would see the following consistent picture in the simulations: a decrease in surface temperature over the Amazon region that forces a similar decrease in low-level atmospheric convergence toward the region and results in decreased rainfall. But contrary to this theory, most of the GCMs simulate an increase in surface temperature, a decrease in lowlevel convergence, and a decrease in rainfall. Given that models simulate an increase (instead of a decrease) in surface temperature, Eltahir and Bras [1993] suggested that the decrease in large-scale low-level atmospheric convergence can only be explained as the result of an initial reduction in local surface rainfall and a consistent reduction in the associated heating of the upper atmosphere. Hence the change in largescale circulation is a consequence of an initial negative change in rainfall and is not the cause of the initial change in rainfall. However, following an initial reduction in local rainfall, the resulting decrease in large-scale atmospheric convergence provides a positive feedback that would decrease rainfall even further. Having, excluded the large-scale forcing of local rainfall changes, the same question remains: what is the primary factor that causes the initial reduction in local rainfall? One reasonable hypothesis can be offered based on the theory and observations presented in this paper. We argue that the initial changes in local rainfall following deforestation are forced, primarily, by the changes in local surface conditions: deforestation reduces the wet-bulb temperature and hence triggers a reduction in rainfall.

Although the impact of deforestation on surface conditions is of primary importance for understanding how deforestation affects regional climate; almost all the numerical simulations on the deforestation problem are reported without reference to the changes in specific humidity or wet-bulb temperature. The study of Nobre et al. [1991] is the only exception: their results as well as the results from Eltahir and Bras [1994] are shown in Table 1. To estimate the impact of deforestation on wet-bulb temperature, we perform the following analysis. The wet-bulb temperature is related to temperature and humidity through

$$
C_{p} T_{w}=C_{p} T+L(r-r w)
$$

where $r_{w}$ is the saturation mixing ratio at temperature $T_{w} ; r_{w}=$ $e_{w} / p$, where $e_{w}$ is saturation vapor pressure. At climatic timescales and neglecting variability in surface pressure, we derive

$$
C_{P} \overline{T_{w}}=C_{P} \bar{T}+L\left(\bar{r}-\frac{\overline{e_{w}}}{p}\right)
$$

where the overbar denotes climatic averages. Based on this relation, it can be shown that

$$
\begin{aligned}
& \frac{\partial \overline{T_{w}}}{\partial \bar{T}}=\frac{C_{P}}{\left[C_{P}+\frac{L}{p} \frac{\partial \overline{e_{w}}}{\partial \overline{T_{w}}}\right]} \\
& \text { and } \\
& \frac{\partial \overline{T_{w}}}{\partial \bar{r}}=\frac{L}{\left[C_{P}+\frac{L}{p} \frac{\partial \overline{e_{w}}}{\partial \overline{T_{w}}}\right]}
\end{aligned}
$$

Indeed, the Clausius-Clapeyron relation governs the sensitivity of wet-bulb temperature to changes in temperature and humidity. This dependence comes through the derivative of saturation vapor pressure with respect to temperature. At an average wet-bulb temperature of about $23^{\circ} \mathrm{C}$, which is typical for the Amazon region, the value of this derivative is about 1.8 $\mathrm{mbar} /{ }^{\circ} \mathrm{C}$. This value is used in equation $(10)$ to estimate the magnitudes of the changes in wet-bulb temperature due to changes in temperature and specific humidity in the two simulations of Table 1. In general, the magnitude of the change in wet-bulb temperature following deforestation is rather small. However, as illustrated by Figure 9, the frequency of storms is highly sensitive to changes in wet bulb temperature. This sensitivity is sufficient to cause an initial reduction in rainfall following deforestation. The latter triggers further feedbacks that may involve the large-scale circulation.

The second case study is the impact on rainfall due to development of irrigation in the Columbia basin project. The size of the project is 200,000 hectares that was developed in the period 1950 - 1965. The water supplied for irrigation is about 3 $\mathrm{km}^{3}$ per year. Stidd [1975] analyzed summer (July and August) rainfall measured at about a hundred stations located within 240 kilometers from the center of the project. The stations within the Columbia basin were classified as target stations and these are located, roughly, within $200 \mathrm{~km}$ from the center. The rest of the stations are the control stations. The measure used in the analysis is the ratio of mean summer rainfall for the period (1959 - 1973) to the normal, which is estimated by the mean for the period (1931 - 1950). This measure, when computed from the target stations, is significantly larger than that for the control stations. One plausible hypothesis to explain these observations would be to argue that large-scale irrigation enhances vegetative cover and soil moisture, increases the wet-bulb temperature, and as a result enhances convective rainfall in summer. However, the above discussion of these two cases can only provide hypotheses regarding the mechanisms through which changes in land cover may impact rainfall patterns. Further research, using observations and model simulations, is needed to further test these hypotheses and to clarify the impact of changes in vegetative cover on wet-bulb temperature.

Table 1. Changes in Temperature, Humidity, and Wet-Bulb Temperature Due to Deforestation in the Amazon Region

\begin{tabular}{lcc}
\hline \multicolumn{1}{c}{ Study } & $\begin{array}{c}\text { Nobre et al. }[1991] \\
\text { (at 850 mbar) }\end{array}$ & $\begin{array}{c}\text { Eltahir and Bras [1994] } \\
\text { (at the Surface) }\end{array}$ \\
\hline Change in temperature, ${ }^{\circ} \mathrm{C}$ & +1 & +0.6 \\
Change in specific humidity, $\mathrm{g} / \mathrm{kg}$ & -1 & -1.2 \\
Change in wet-bulb temperature, ${ }^{\circ} \mathrm{C}$ & -0.25 & -0.42 \\
\hline
\end{tabular}




\section{Conclusions}

1. The analysis presented in this paper suggests that the triggering of moist convection and storm rainfall amount can be described by using simple linear functions of surface wet-bulb temperature. However, the proposed concepts are relevant to convective storms that are forced and maintained locally due to the conditional instability in the vertical distribution of atmospheric temperature. The same concepts are not relevant to rainfall storms that are forced by large-scale circulations such as monsoons or frontal systems.

2. The observations on rainfall and wet-bulb temperature from the Amazon region are consistent with the proposed relationship between the two vanables and confirm that both the likelihood of occurrence of a convective storm as well as the total storm rainfall increase with surface wet-bulb temperature.

3. A simple analysis on the sensitivity of convective storms to changes in the climatology of wet-bulb temperature indicates that frequency of storms is a more sensitive variable compared to the average storm rainfall. A degree cooling in the average wetbulb temperature would result in about $50 \%$ reduction in the frequency of storms as compared to a $15 \%$ reduction in the average storm rainfall.

4. The proposed relation between surface wet-bulb temperature and rainfall has been applied in exploring the pathways relating changes in vegetative cover over the Amazon river basin (deforestation), Columbia River basin ( development of irrigation), and the impact on rainfall patterns. Different hypotheses are developed to explain the predicted reduction in convective rainfall in the Amazon and the observed increase in rainfall over the Columbia River basin. Future research will focus on further tests of these hypotheses.

Acknowledgments. The ARME data set used in this study was collected as part of a collaborative effort among the National Environmental Research Council. the United Kingdom, the Conselho Nacional de Desenvolvimento Cientifico et Technologico (CNPq), Brazil. and the Britısh Council.

\section{References}

Bastable, H. G., W. J. Shuttleworth, R.L.G. Dallarosa, G. Fisch and C. A Nobre, Observations of climate, albedo and surface radiation over cleared and undisturbed Amazonian forest, Int. J. Climatol.. 13, 783$796,1993$.

Betts, A K., A new convective adjustment scheme. Part I : Observational and theoretical basis. QJ. R. Meteorol. Soc., 112, 677-691, 1986.
Changnon, S. A, Rainfall changes in summer caused by St. Louis, Sclence. 205, 402-404, 1979.

Dickinson. R. E., and P. Kennedy, Impacts on regional climate of Amazon deforestation, Geophys. Res. Lett., 19, (19), 1947-1950, 1992.

Diremeyer, P. A, and J. Shukla, Albedo as a modulator of climate response to tropical deforestatıon. J. Geophys. Res., 99, 20,863-20,877, 1994

Eltahir, E. A. B., A feedback mechanism in annual rainfall, Central Sudan, J. Hydrol., 110, 323-334, 1989.

Eltahir, E. A. B., The role of vegetation in sustaining large scale atmospheric circulations in the tropics, J. Geophys. Res., 101, 42-55, 1996.

Eltahir, E. A. B., and R. L. Bras, On the response of the tropical atmosphere to large-scale deforestation. Q. J. R. Meteorol. Soc. , 119, 779-793, 1993.

Eltahir, E. A. B., and R. L. Bras, Sensitivity of Regional Climate to Deforestation in the Amazon Basin, Adv. Water Resour., 17, 101-115. 1994.

Henderson-Sellers, A, R. E. Dickinson, T. B. Turbidge, P. J. Kennedy, K. McGuffie, and A. J. Pitman, Tropical deforestation: Modelling local to regional scale climate change, J. Geophys. Res., 98, 7289-7315, 1993.

Lean J., and P. R. Rowntree, A GCM simulation of the impact of Amazonian deforestation on climate using improved canopy representation, Q.J. R. Meteorol. Soc. ,119, 509-530, 1993.

Lean, J., and D. A. Warrilow, Simulation of the regional climatic impact of Amazon deforestation, Nature, 342, 41 1-413, 1989.

Lloyd, C. R., The temporal distribution of Amazonian rainfall and its implications for forest interception. Q. J. R. Meteorol. Soc., 116, 1487$1494,1990$.

Manabe, S., J. Smagorinsky, and R. F. Strickler, simulated climatology of A General Circulation Model with a hydrological cycle, Mon. Weather Rev., 93(12), 769-798, 1965.

National Research Council (NRC), Opportunities in the Hydrologic Sctences, 348 pp. National Academy Press, Washington, D. C., 1991

Nobre, C. A., P. J. Sellers, and J. Shukla, Amazonian deforestation and regional climatic change, J. Climate, 4, 957-988, 1991.

Segal, M., R. Avissar, M. C. McCumber, and R. A. Pielke, Evaluation of vegetation effects on the generation and modification of mesoscale ciculations, J. Atmos. Sct., 45(16), 2268-2286, 1988.

Shuttleworth, W. J., Evaporation from Amazonian rainforest, Philos. Trans. R. Soc. London, B, 233, 321-346, 1988.

Stidd, C. K., Irrigation increases rainfall?, Science, 188, 279-280, 1975.

Williams, E., and N. Renno, An analysis of the conditional instability of the tropical atmosphere, Mon. Weather Rev., 121(1), 21-36, 1993.

Zawadzki, I. I., and C. U. Ro, Correlations between maximum rate of precipitation and mesoscale parameters. J. Appl. Meteorol., 17, 1327$1334,1978$.

Zawadzki, I. I., E. Torlaschi, and R. Sauvageau, The relationship between mesoscale thermodynamic variables and convective precipitation. $J$. Appl. Meteorol., 38, 1535-1540, 1981.

E. A. B. Eltahir and J. S. Pal, Ralph M. Parsons Laboratory, Department of Civil and Environmental Engineering, Massachusetts Institute of Technology, Room 48-207, Cambridge, MA 02139. (email: eltahir@mit.edu; jpal@mit.edu)

(Received October 17, 1995; revised February 25, 1996; accepted April 25, 1996.) 